\title{
Systemic Design: How to Compete by Leveraging the Value System*
}

\author{
Fabrizio Mosca ${ }^{* *}$ \\ Paolo Tamborrini ${ }^{* *}$ \\ Cecilia Casalegno ${ }^{* * *}$
}

\begin{abstract}
Sustainability interfaces with the economy through the social and ecological consequences of economic activities. Furthermore, the culture of food lends strategic value to the food system with its economic, social, cultural, and environmental implications. Systemic Design (SD) designs material and energy flows, investigating positive changes in productive processes and activating a new economic model based on open industrial cycles. Firms can build new and strong competitive advantages for themselves and for the territory in which they operate, and this result can be achieved going beyond environmental concerns (environmental responsibility).
\end{abstract}

Keywords: Global Competition; Innovation; Systemic Design; Coffee Market; Corporate Social Responsibility; Business Model; Blue Economy

\section{From Corporate Social Responsibility to the Territory Value Creation: The Management of Sustainable Development}

Nowadays, if a firm wants to be effective in meeting its stakeholders' needs, it must leverage responsible, ethical, and sustainable behaviors, since we are talking about a globalization process bringing changes involving a human being which is, at the same time, huge and citizen in a certain territory (Brondoni, Pepe 2007). This is valid also when talking about markets and customers (Torres et al. 2012; Vallaster et al. 2012; Macleod 2001; Mohr et al. 2001). When a firm acts in the abovementioned fields, the definition of the sum of the concerns affecting its strategy is Corporate Social Responsibility (CSR), which has been actively implemented by companies over the last few decades (Candelo et al. 2014). If we look at the traditional definition of CSR, the approach is mainly based on embedding sustainable goals, in terms of environment and society, in for-profit strategies (Brondoni 2003). In other words, firms realize that the more their strategy

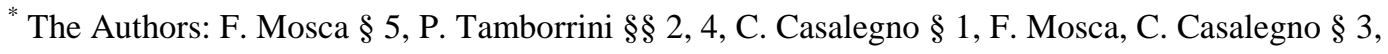
F. Mosca, P. Tamborrini 6.

** Associate Professor of Management, University of Turin (fabrizio.mosca@unito.it)

** Associate Professor of Design, Politecnico di Torino (paolo.tamborrini@polito.it)

*** Assistant Professor of Management, University of Turin (cecilia.casalegno@unito.it)
}

Edited by: ISTEI - University of Milan-Bicocca

ISSN: 1593-0319

Mosca Fabrizio, Tamborrini Paolo, Casalegno Cecilia (2015) Systemic Design: How to Compete by Leveraging the Value System, Symphonya. Emerging Issues in Management (symphonya.unimib.it), n. 2, pp. $42-56$. 
is guided by social and environmental concerns and the more their personality interacts with the environment (Brondoni, Pepe 2007), the more it can lead to sustainable economic results. These economic results are, first of all, to the benefit of the firms, but they also apply to the systems in which the firms have headquarters and production plants. CSR also involves the aspect of firm communication as a part of firm strategy. Since the focus is on strategy, corporate communication should lead to enhanced company reputation, which goes beyond the objectives of marketing communication but, at the same time, comprises them. In this way, stakeholders know about the firm's social and environmental commitment and its willingness to share its values with the local population. CSR deals with the concept of shared value, which means that firms perform a set of activities going beyond profit results and trade-off with social concerns. By doing that, firms can boost their competitiveness and, at the same time, have an impact on the social and environmental value of their territory (Porter, Kramer 2011).

The basic idea is that sustainability interfaces with the economy through the social and ecological consequences of economic activities (Daly, Cobb 1989).

According to Costanza and Patten (1995), the meaning of sustainability comes from biology: «Biologically, sustainability means avoiding extinction and living to survive and reproduce. Economically, it means avoiding major disruptions and collapses, hedging against instabilities and discontinuities. Sustainability, at its base, always concerns temporality, and in particular, longevity». The pursuit of longevity drives companies to seek ever-closer integration with the territory in which they operate. Long-term positive results can be achieved and protected only when a firm becomes aware that it is an active part of society and that its production processes have an impact on the environment. When we apply the concept of sustainable results to the environment, society, and the economy, we have what Elkington (1999) called Triple Bottom Line (TBL), which has gained acceptance as a new instrument to measure company performance according to three key indicators: economic, environmental, and social (Hubbard 2009). The aspect which ought to be underlined is that firms pay attention also to the environmental and social value they produce, or possibly destroy (Elkington 2004). Commitment to TBL concepts is emphasized and included in international, national, and local policies and protocols. Moreover, it is mentioned in the mission of countless firms and NGOs (Büchi et al. 2014): sustainable development is a major goal which organizations strive to attain. Even the United Nations has published a set of Millennium Development Goals (MDGs), to be achieved by 2015. These goals concern regions' economic development and the elimination of poverty, addressing human rights, health, education, and environmental questions. According to Seelos and Mair (2005): "efficiencies of markets, combined with the resources and managerial expertise of large multinationals, are considered crucial success factors in achieving these goals". Yet, a parallel element of the business process ought to be mentioned too: CSR is the strategy. From CSR we move to the concept of Blue Economy (Pauli 2010), which aims to transform the economy of society by changing the basis on which well-being is founded: from resource scarcity to abundance (Kathijotes 2013). In what way? By reusing industrial waste and recycling materials previously identified as waste, but which contain, in most cases, important elements for new business processes. Obviously, this requires new 
managerial skills and the ability to use innovative technologies to exploit what is usually discarded by production processes and by society (Pauli 2010).

The concept of CSR is linked to that of the green economy. Unlike in the green economy, process or product innovation for the wise management of resources no longer means investing again or constantly looking for funds from governments or institutions. Going beyond the 'green' economy, we approach the concept of 'blue' economy, which is based on the fact that, through the use of all its resources, a firm can work in full integration with the environment. This is done not only to have a lower impact on the environment but also to generate new business, with new chances to increase value creation for the local area by changing and improving the value system. In essence, technological research is inspired, in this case, by the functioning of nature (Pauli 2010). Firms act through biomimicry strategies. By following these principles and by using less capital, firms can generate major profit flows and build, at the same time, social capital, enhancing the effectiveness of the value chain.

Several case studies and an analysis of the literature (Palmberg et al. 2000; Simpson et al. 2004; Vives 2006; Wahba 2008; Babiak, Trendafilova 2011) highlight the clear and strong involvement of firms in social and environmental problems. However, little has been said so far about creating new business by leveraging waste materials coming from production processes, on the one hand, and about the use of goods and services produced or provided by large companies, on the other hand.

The present research shows that firms can build new and strong competitive advantages for themselves and for the territory in which they operate, and this result can be achieved going beyond environmental concerns (environmental responsibility). Through the application of what we can call systemic design (SD), with the creation of a new social consciousness able to go beyond marketing and branding purposes, firms can affect society by creating new business.

This is particularly true when looking at the food industry. The system thinking is progressing slowly and the literature does not help when the concept of food recycling is analyzed.

\section{Systemic Design as Accelerator of New Local Businesses}

The rapid evolution of the worldwide scenario - together with climate change, biodiversity loss, depletion of resources, and rapid technological and social development - calls for radical changes. The above factors have caused the transformation of seasonal and territorial activities into processes which have been completely removed from their usual space and time and placed in certain areas due to economic and logistic factors (such as low cost of labor or proximity to motorways). As a result, a steady impoverishment of the soil has occurred. Although the current environmental, economic, and social crisis calls for radical changes to ensure the survival of mankind, there are new prospects which encourage 'designers' to rethink the entire socio-productive system in more sustainable terms.

Furthermore, the culture of food lends strategic value to the food system with its economic, social, cultural, and environmental implications (Barbero, Tamborrini 
2014). According to the Millennium Ecosystem Assessment, published by the United Nations in 2004, most unsustainable human activities are related to the agrifood sector.

Food is not to be conceived merely as a product, without considering the coordination and integration of all the functional, symbolic, cultural, technical, and manufacturing factors linked to it. It is necessary to design and develop flows running from one system to another by means of a continuous metabolism which decreases the carbon footprint and activates the local economy. This approach is called Systemic Design (SD) and it designs material and energy flows, investigating positive changes in productive processes and activating a new economic model based on open industrial cycles (Bistagnino 2011).

Production systems become efficient and sustainable when they imitate nature, and the guidelines of SD are as follows:

- the output (waste) of a system becomes the input (resource) of another, creating an increase in cash flow and new job opportunities;

- relationships generate the system itself: each relationship contributes to the system and can develop within the system or outside of it (Tamborrini 2014);

- $\quad$ self-producing systems support and reproduce themselves, which allows them to define their own action paths and to jointly co-evolve;

- act locally: the local context is fundamental. Acting locally values local resources (human, cultural, and material) and helps to solve local problems by creating new opportunities;

- people are at the center of each project to be connected to their environmental, social and cultural context.

This kind of study starts with a holistic survey of the current situation, clearly outlining all the steps and actions undertaken or undergone by the context in question. The quantities of what enters the system are analyzed, along with what happens inside the system, the quantities of what comes out of it, their destination, and possible uses. In addition, the players involved in the system, their nature, know-how, available technologies, as well as their communication are studied.

Data on incoming and outgoing flows of materials and energy are provided. Information about their nature, their origin and their future use or destination sheds light on the process during which they undergo different transformation phases. As a result, we obtain a global vision of the process and of the overall relationships which characterize the system and make it work.

Indeed, an approach focusing on single parts proves to be in contrast with the dynamism of the whole and with the 'traditional' efficiency of natural systems, which we can purposefully take as an example. The safeguarding of this global vision can be attained by drawing a graphic chart, allowing us to retrace the flows of material and energy and their use, the knowledge capital, the relationships among the actors, and the contextualization of the system being analyzed. Moreover, physics, biology, chemistry, mathematical sciences, history, and economics are the indispensable tools for this analysis (Tamborrini 2009), which is carried out by a designer. He/she must focus on understanding causality relationships linking different phenomena and on identifying planning process priorities, in line with the information provided by nature, an unparalleled model of efficiency (Barbero, Cozzo 2009). 
Thus, systems design becomes a matter of culture and ability to modify reality based on the planned processing of available resources. This is carried out in accordance with certain schedules and with results that are established beforehand (Celaschi 2008).

\section{From CSR to Value System Enhancing: A Glance to the Coffee Industry}

It is extremely interesting to note that great importance has been given to food, in managerial and business terms, and much has been written on the potential re-use of waste from the food and beverage industry. For instance, a number of articles illustrate how to process food waste as an attractive renewable source (GerbensLeenes et al. 2003; Parfitt et al. 2010; Modh Yasin et al. 2013; Mirabella et al. 2014). This shows that, differently from other intangible assets, concerns about the environment are not just something which is used to beat the competition on the market but they must be the strategy. Despite widespread interest in this topic, research has mainly focused on various aspects of the concept of sustainability but, in most cases, interactions have not been described or studied (Gerbens-Leenes et al. 2003). Furthermore, worldwide valid KPIs are difficult to find, even though several valuable attempts have been made in this sense. Table 1 shows the most relevant ones (according to the University of Turin data whorehouse rating) considering 'sustainability', 'production' and 'food and beverage' as keywords.

Table 1: Instances of valid attempts in food sustainable production

\begin{tabular}{|c|c|c|}
\hline $\begin{array}{l}\text { Author(s) and publication } \\
\text { year }\end{array}$ & Paper title & Topics and aims \\
\hline Heller, Koeleian (2003) & $\begin{array}{l}\text { Assessing the sustainability of } \\
\text { the US food system: a life } \\
\text { cycle perspective }\end{array}$ & $\begin{array}{l}\text { System-based solutions in } \\
\text { order to find KPIs to evaluate } \\
\text { every PLC phase }\end{array}$ \\
\hline Gerbens-Leenes et al. (2003) & $\begin{array}{l}\text { Design and development of a } \\
\text { measuring method for } \\
\text { environmental sustainability in } \\
\text { food production systems }\end{array}$ & $\begin{array}{l}\text { Identification of key global } \\
\text { issues relevant for food } \\
\text { production and developing of a } \\
\text { measuring method based on a } \\
\text { small set of system indicators }\end{array}$ \\
\hline Green, Foster (2005) & $\begin{array}{l}\text { Give peas a chance: } \\
\text { Transformations in food } \\
\text { consumption and production } \\
\text { systems }\end{array}$ & $\begin{array}{l}\text { Social and ethical aspects must } \\
\text { affect innovation. How to } \\
\text { reach a sustainable production: } \\
\text { analysis of the supply chain in } \\
\text { order to understand when } \\
\text { production and consumption } \\
\text { can be sustainable }\end{array}$ \\
\hline Gagliardi et al. (2014) & $\begin{array}{l}\text { Evaluation and design of } \\
\text { innovation policies in the agro- } \\
\text { food sector: An application of } \\
\text { multilevel self-regulating } \\
\text { agents }\end{array}$ & $\begin{array}{l}\text { Evaluation of innovative } \\
\text { policies on the territory, above } \\
\text { all concerning the territory } \\
\text { organic agriculture promotion }\end{array}$ \\
\hline Colvin et al. (2014) & $\begin{array}{l}\text { In search of systemic } \\
\text { innovation for sustainable } \\
\text { development: a design praxis } \\
\text { emerging from a decade of } \\
\text { social learning inquiry }\end{array}$ & $\begin{array}{l}\text { Leading the ecological and } \\
\text { social system is possible } \\
\text { through the innovation and the } \\
\text { reliance. Comparative analysis } \\
\text { of three cases }\end{array}$ \\
\hline
\end{tabular}




\begin{tabular}{|l|l|l|}
\hline Veflen Olsen (2015) & $\begin{array}{l}\text { Design Thinking } \\
\text { and food innovation }\end{array}$ & $\begin{array}{l}\text { How the DT can contribute to } \\
\text { the food industry innovation } \\
\text { and which are the outputs }\end{array}$ \\
\hline
\end{tabular}

Moreover, few research papers investigate how firm management can build resilience for the social and ecological system (Colvin et al. 2014). Instead, when we talk about firms and especially when we look at family businesses, we should think about how much a player can do in terms of enhancing the territory's value system. The present research, in particular, focuses on the territory where Lavazza SPA is located, while also investigating how important the production, roasting, and selling of coffee is at the global level. If we consider that the total production of exporting countries amounted to 141 million bags in 2014 (60 kilos/bag), according to 2015 ICO statistics, we can easily understand that coffee is one of the most valuable trading commodities in the world (Locke et al. 2010). Between 17 and 20 million families produce and sell this product in developing countries and $80 \%$ of all coffee is produced by smallholder families; in addition, a coffee bean might change hands around 150 times before it is sold (Locke et al. 2010). These data show that the coffee market has a strong environmental, social, and economic impact on the territory. This is why major coffee roasters and sellers feel involved in CSR issues and have implemented a range of fair trade projects (as shown in Table 2). When analyzing the involvement in social issues of worldwide players operating on the coffee market, it is clear that concerns are mostly related to the supply chain, for obvious reasons linked to the economies of the countries producing coffee beans. From Illy - for which fair trade is somehow linked to the elegance of coffee - to Starbucks - which has built its value proposition around the concept of fair trade - to the Nespresso brand - which has made sustainable quality one of its fundamental concepts -, each of the large players is trying to increase the value generated by its system of upstream relations. The society of the countries producing coffee can benefit from fair trade, but this is not the only beneficial aspect. Indeed, ethical values and stainless steels are strictly linked to major coffee brands.

Table 2: Major coffee roasters attempts in sustainable development

\begin{tabular}{|l|l|l|}
\hline Company & CSR most known initiatives & 'Blue economy' initiatives \\
\hline Illy & $\begin{array}{l}\text { Responsible relationships with } \\
\text { suppliers. Fair trade. }\end{array}$ & \\
\hline Starbucks & $\begin{array}{l}\text { Sustainable supply chain - } \\
\text { 'C.A.F.E practices' }\end{array}$ & \\
\hline Lavazza Spa & Tierra! project & $\begin{array}{l}\text { 'The Flavours of coffee } \\
\text { grounds' project }\end{array}$ \\
\hline Nespresso & $\begin{array}{l}\text { 'AAA Sustainable Quality } \\
\text { Program' }\end{array}$ & \\
\hline
\end{tabular}

The involvement of Lavazza SPA in the territory where the company was founded has represented, in recent years, an important part of its business strategy. In particular, Lavazza is a leading company in the coffee industry and represents a point of reference for companies in the same sector, first, and involved in the same territory, at a second glance. From the Innovation Center project, with the Politecnico di Torino, to the Nuvola project, the focus has been not only on 
corporate responsibility, for what concerns local environmental and social impact, but also on the strengthening of the value system - above all in relation to the project carried out with the Politecnico di Torino Therefore, new business opportunities are taken into account and technological innovations are developed with the contribution of local people, young local innovators.

\section{The Use of Spent Coffee Grounds (SCG): How to Turn Waste in New Business Chances. A Concrete Project}

Among the projects in which the Politecnico di Torino has been involved, this section presents a case study on The Flavours Of Coffee Grounds, led by Politecnico ${ }^{1}$ and implemented in 2012 in collaboration with Lavazza SPA. The project is developed by the Politecnico di Torino (Department of Architecture and Design) in collaboration with the largest Italian producer of roasted coffee and its goal is to evaluate the feasibility of SCG valorization in coffee bars.

The project is mostly business oriented, although it also has a strong educational and social component. It addresses the matter of collecting coffee waste from local cafés in order to generate new industrial activities. As mentioned, projects such as this also have a strong educational aspect, because they make it possible not only to be aware of environmental problems but also to be part of their solution. The theoretical model for this project focuses on increasing the value of coffee waste as well as on designing an entire complex system. SCG need to be disposed of in a controlled way, because the residual caffeine, tannins and polyphenols might have negative effects on the environment.

In addition to the chemicals listed above, SCG contain other elements, such as minerals, melanoidins, lipids and waxes, lignin, proteins, ashes and polysaccharides (cellulose and hemicellulose are slightly less than 50\% in anhydrous SCG), which can be put to good use.

The aim of the project combines the creation of a system which gives new life to SCG with the educational and social aspects related to the valorization of waste. SCG need to be split into their two main components (secondary raw materials), i.e. oils and used coffee grounds, each of which has different sectors of application.

Through the SD approach, all the activities can be organized in a sequential and interrelated way, so that the output of one process becomes the input of several other ones, without wasting secondary materials. The goal is to plan a range of activities which might be applied at the industrial level in the near future.

The pilot experiment involves 114 coffee bars in the city center of Turin, with a total amount of $735 \mathrm{~kg}$ of SCG collected per day. These initial quantities are essential to design the collection system and to define the real business model, in order to apply it swiftly and effectively.

In cafés, SCG are usually collected in a drawer under the coffee machine. In order to start the collection of this waste, bartenders should be informed that they must be careful not to throw other waste into the same drawer, as this could contaminate SCG. Special bins have been designed for this project in order to meet transportation and dimension requirements. It is necessary to systematize the activities (Figure 4), to understand what should be done first, and to identify the required operations and the characteristics of the materials after such operations. An 
analysis of the products which can be obtained from SCG reveals, for example, that none of the activities require entire SCG. In some cases only the oils are needed, some other processes rely solely on the cellulose material and the presence or absence of oils does not lend any added value, while other activities require SCG to be anhydrous or micronized.

Therefore, it has emerged that oil extraction should be carried out first and spent coffee grounds could be used at a later stage for other activities, by performing certain treatments on them. Design choices have been made by investigating the characteristics and experiences of the territory, according to the SD guidelines. The study of SCG collection and its logistics is a fundamental aspect of this project. It has been necessary to devise an efficient collection system, in collaboration with the local collection authority, in order to pick up SCG from cafés without disrupting their business. Times of the day with fewer customers have been identified and a system of bins has been designed, dividing cafés based on their weekly production of SCG.

The number of collections has been calibrated according to this parameter and taking the perishable nature of this raw material into account.

The designed collection system uses 4 cargo-bikes, both to reduce environmental impact and to ensure effective operations also in historic centers and pedestrian areas. This activity will generate new employment in the territory of application.

As regards the activity of extraction, it has been decided to avoid using supercritical fluid (supercritical $\mathrm{CO}_{2}$ ), which, besides its very high costs in terms of equipment, raw materials, and energy consumption, requires highly qualified personnel.

The process is applied to the $735 \mathrm{~kg}$ of SCG in order to obtain 70 liters of oil per day, which can be used in the cosmetic and pharmaceutical sectors or, through trans-esterification, to produce biodiesel. These products are the most profitable aspect of the project. The outputs of this process are SCG without their oils and water, which can have several other uses, described below. For instance, they can serve as constituents of the substrate needed to grow edible mushrooms. SCG contain cellulose, hemicellulose and lignin, materials suitable for the growth of mushrooms, but production increases if they are combined with agricultural byproducts, since SCG are compact and hinder the diffusion of the so-called mycelium, increasing incubation times. In Italy, since 2008, the Politecnico di Torino has been carrying out research studies on the re-use of SCG for the production of edible mushrooms.

After oil extraction, $665 \mathrm{~kg}$ of SCG are obtained, which are mixed with $190 \mathrm{~kg}$ of bagasse and used as substrate for growing mushrooms. In the cultivation of Pleurotus Ostreatus mushrooms, the outputs of two processes contribute to creating a product which has market value. The substrate is inoculated with $25 \mathrm{~kg}$ of mycelium and stored in the dark for several days, at the end of which the fruiting of the mushrooms takes place. A portion of the substrate produced is packaged to be sold as a kit for growing mushrooms at home, while the mushrooms obtained from the production line are sold to local restaurants and any excess is dried and sold to retail stores.

The whole process yields 30 mushroom kits per day, $70 \mathrm{~kg}$ of fresh mushrooms, and $230 \mathrm{~kg}$ of mushrooms which are dried, losing $90 \%$ of their moisture and producing $23 \mathrm{~kg}$ of dried mushrooms (packed in small 50-gram bags). The 
mushroom growing kits are sold to customers who are sensitive to environmental issues and keen on self-producing healthy food. The fresh mushrooms are intended for canteens, restaurants and the same bars which provide SCG, with special agreements. The mono-portion bags of dried mushrooms are intended for the traditional retail sector.

However, the raw material which has produced the mushrooms, $510 \mathrm{~kg}$ of exhausted substrate, does not reduce its volume, and this raises the question of finding a subsequent use for it.

After the oil is extracted, a part of SCG is not used for mushroom production but can be reduced to micrometric size through a process which, in addition to pulverizing the material, eliminates any residual moisture. This new material has many uses as reinforcement/additive in the production of recycled paper (which retains the grain and characteristic color of SCG), new textile fibers, bricks, activated carbon, screen printing inks, as well as for the purification of water from heavy metals and for the removal of dyes.

After oil extraction, another part of SCG can be intended for the production of biopolymers, with 95\% SCG and the remaining 5\% consisting of polylactic acid and a mixture of paper. This type of pellet can be used to manufacture new objects and panels by compression molding.

The substrate exhausted after mushroom production (consisting of SCG, spent grain, and mycelium) can have various end-of-life uses. It can be hot pressed to make acoustic panels, or micronized and used as an additive in the production of recycled paper, as mentioned above, but it can also be employed in the production of vermicompost and of pellets for domestic heating. It should be pointed out that combustion is not the best solution for what concerns waste disposal, especially when said waste still has productive value and, consequently, market value.

The pelletizing process, in this case, has been chosen only for the $510 \mathrm{~kg}$ of exhausted substrate, trying to exploit SCG as much as possible before burning them. After all the previous process, this appears to be the most economical and profitable choice for this material. Through combustion, it becomes ash and can serve as fertilizer for domestic use, since it has good manuring properties.

Regarding the systemic project to re-use SCG collected from cafés, the study has been carried out to also include cost and revenue estimates, showing that large profit margins can be achieved. 
Figure 1: Systemic Scheme of Activities

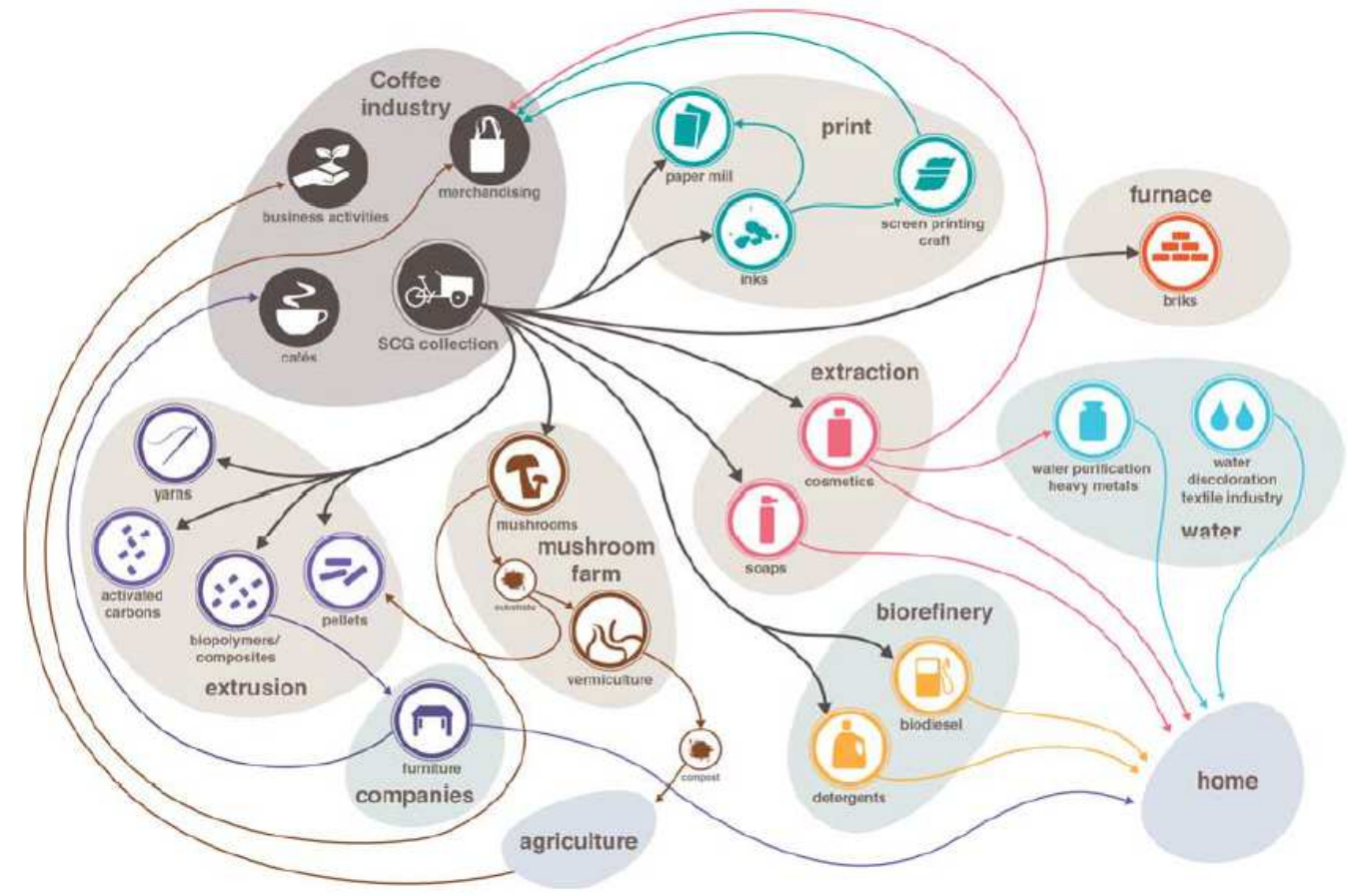

In particular, two business plans have been developed with different levels of complexity. The first is immediately applicable and includes only the production of mushrooms and the pelletizing process, while the other would require further testing of the real market value of the oil produced and further investigation of extraction techniques without the use of solvents (currently under experimentation).

This study, therefore, aims to promote a sustainable and economically active development, creating added value for the places where it is implemented in terms of: employment, reduction of disposal quantities and costs, use of secondary raw materials, development of a network of new productions, development of knowhow and new professional profiles, creation of new products by companies which will study how to use the new materials in their business, and income from new activities, with consequent investments in $R \& D$. This approach seeks to reduce transport emissions and increase economic value for the local community.

The system is able to generate a series of relationships with local stakeholders, involving those responsible for waste management, with agreements to transfer waste on the road.

The other beneficiaries of the project are bartenders, brewers, some local SMEs, such as those producing inks, cosmetics and pharmaceuticals, as well as paper mills, wastewater operators, and producers of air filters. Some of these actors will be involved in the pilot study but, by extending the project, for example, to the entire city of Turin, the amount of waste might support the activation of several other relationships with companies. 


\section{Win-Win Strategy in Systemic Design: A Business Model Hypothesis}

The new business opportunities analyzed above lead to some hypotheses which can represent milestones for the creation of a new sustainable business model. Large firms can follow this model to strengthen their ties with the territory, where they can find consumers who are aware of ecological and social issues.

In view of these ecological and social priorities, the SD approach can help:

a) to focus on operational activities for product and process development, compliance with environmental standards, and how to use waste coming from production and consumption processes;

b) to stimulate managers to organize production in a way which integrates with other downstream processes focusing on the reuse of waste.

Considering the impact which a coffee roasting company has on the community, the present research tries to model a business hypothesis deriving from the approach described above.

First of all, it is worth underlining that family-run firms display greater involvement and stronger ties with the territory where they are located (Alsos et al 2014). They can facilitate local business growth due to their entrepreneurship.

Regarding the SCG project, as shown in figure 2, integration between Lavazza and the local territory can give rise to a win-win strategy.

Figure 2: A Sustainable Business Model Starting from the Waste

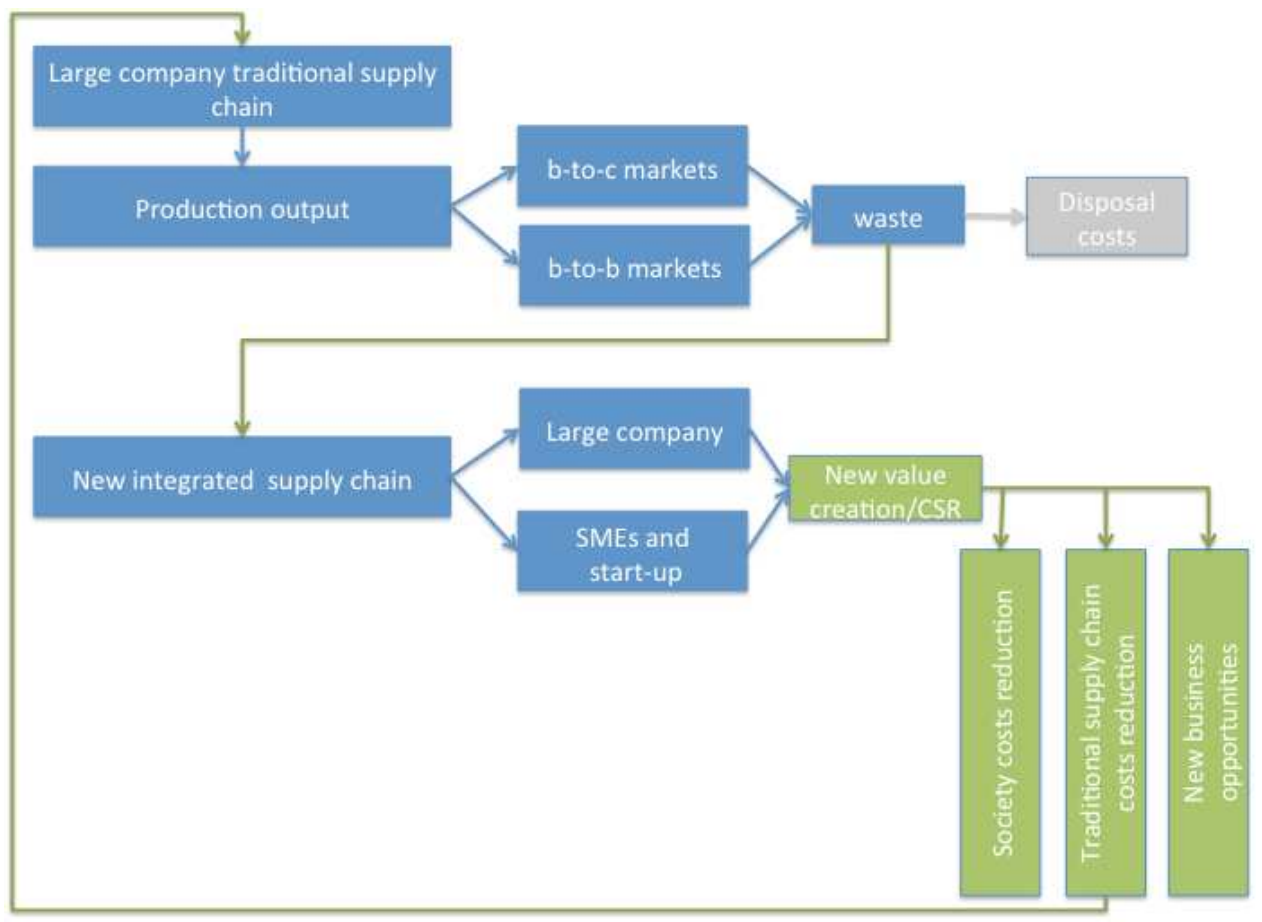

On the one hand, the firm continues to pursue its ethical business model. The idea behind the project is a natural consequence of the actions related to corporate social responsibility, already considered. In this case, corporate responsibility is not only embedded in the 'fabric' of the strategy, but the responsible company becomes a catalyst and promoter of new businesses. In other words, the resources recovered 
through the project described in this paper can be re-injected into the territorial system, leading to new forms of value creation. It is a system of agents which generate value for the region in economic and social terms, through the creation of new business and new jobs. Moreover, the firm plays a very important role within the local society: it becomes an educator. The business can be aimed at the creation of value for an entire system of agents, limiting waste and environmental impact, but it is also possible to create new business opportunities by leveraging resources previously seen as useless.

So, the large player creates development and helps the territorial system in various ways, providing a wide range of advantages relating to firm reputation as well as society and the environment. This can be a virtuous circle from which a significant number of small local players can profit. The SD approach becomes a strategic CSR element through which the firm simultaneously communicates, to different types of public, its major involvement in environmental and social problems coming from production waste and output consumption.

On the other hand, through SD, the large firm drives its own production process and generates value for other firms - linked to each other within a system -, actively working in waste management.

Through cooperation along the production chain, the main production process, driven by the large firm, is complemented by one or more secondary production processes, often coordinated and/or stimulated by the large firm but directly managed by smaller partner firms or start-ups.

Within this integrated system, the waste generated by the main productive system and/or consumption processes is re-converted and re-used, thus creating new markets or modifying the existing ones.

Hence, economic value is generated:

- for all stakeholders: through the reduction of disposal costs;

- for the territory: the large firm stimulates the development of SMEs (partners) and local start-ups working on secondary productions;

- for the productive system: the large firm generates direct or indirect cost savings through the economical exploitation of waste coming from main productions.

\section{Conclusions and Further Steps}

Within a scenario in which competition has a global place in firm systems whose value chains are tightly integrated, a SD-based model targeting waste management can be a key success factor, as highlighted by the case examined above.

The analyzed case contains very innovative ideas for a smart society based on the concept of the so-called blue economy. This project will have a positive impact firstly on the environment, as it starts from a raw material with high social costs and leads, through its processing, to the development of clean and sustainable processes and industrial activities (in the pilot experimentation on the center of a city, value added is generated by 160 tons of organic waste per year, which means that, potentially, across Italy 100,000 tons/year of waste could be used to manufacture new products). Also the local territory and society will benefit from the project, and improvements in regional competitiveness will be achieved by increasing the skills 
of local technicians and operators involved in the production sector, thus valuing the local economy, territorial productions, and the waste thus produced.

Considering the economic aspect, an increase in the productive activities of the area is expected, along with revenue growth and company investment in R\&D. The project involves numerous local actors, such as producers of inks, cosmetics, and drugs, which may obtain a new raw material that is sourced locally and $100 \%$ biodegradable, thus avoiding the use of synthetic products. Moreover, the aim is to establish a set of start-up activities and provide an innovative approach for production processes which have been lost over time (for example, paper mills and the screen printing craft).

Despite the listed benefits, we realize that this is a pilot project and further steps should measure the impact of SD on the environment. This can be done by identifying KPIs in order to understand the value generated by a firm and by its satellite activities in the interest of the territory as a whole. Moreover, we need to consider other cases, in other geographical areas, and analyze other industries. By carrying out further research, we will be able to determine the real potential which an SD project can have when it leverages the concept of CSR.

\section{Bibliography}

Babiak Kathy, Trendafilova Sylvia (2011) CSR and Environmental Responsibility: Motives and Pressures to Adopt Green Management Practices, Corporate Social Responsibility and Environmental Management, vol 18 n 1, pp. 11-24.

http://dx.doi.org/10.1002/csr.229

Barbero Silvia, Bicocca Miriam (2013) Design for a Sustainable Coffee (Post)Consumption, International Symposium on Sustainable Design (ISSD), Porto Alegre, Brasil, pp. 182-188.

Barbero Silvia, Cozzo Brunella (2009) Eco Design, H.F. Ullmann, Konigswinter.

Barbero Silvia, Tamborrini Paolo (2012) Systemic Design in AgroFood Sector, EN.FA.SI Project,: International Conference on Designing Food and Designing For Food, London.

Bistagnino, Luigi (2011) Systemic Design: Designing the Productive and Environmental Sustainability, Slow Food Editore, Cuneo.

Brondoni Silvio M. (2014) Global Capitalism and Sustainable Growth. From Global Products to Network Globalisation, Symphonya. Emerging Issues in Management (symphonya.unimib.it), n. 1, pp. $10-31$.

http://dx.doi.org/10.4468/2014.1.02brondoni

Brondoni Silvio M. (2013) Innovation and Imitation for Global Competitive Strategies. The Corporation Development Models of US, Japan, Korea, and Taiwan, Symphonya. Emerging Issues in Management (symphonya.unimib.it), n. 1, pp. 12 - 27.

http://dx.doi.org/10.4468/2013.1.02brondoni

Brondoni Silvio M., Pepe Cosetta, Ouverture de 'Ethics in Global Supply Chain', Symphonya. Emerging Issues in Management (symphonya.unimib.it), n. 2, pp. 1-4

http://dx.doi.org/ 10.4468/2007.2.010uverture

Brondoni Silvio M. (2003) Network Culture, Performance \& Corporate Responsibility, Symphonya Emerging Issues in Management (symphonya.unimib.it), n.1, pp. 8-24.

http://dx.doi.org/10.4468/2003.1.02brondoni

Büchi Giacomo, Casalegno Cecilia, Conicella Robreto, Dayon Audry, Pellicelli Michela, Schiesari Roberto (2014) Real Options as Sustainable Business Evaluation Method in the Biotech and Med-Tech Industry. A Qualitative and Empirical Approach, paper presented at 2nd 
International Symposium 'Systems Thinking for a Sustainable Economy. Advancements in Economic and Managerial Theory and Practice"

Candelo Elena, Casalegno Cecilia, Civera Chiara (2014) Meanings and Implications of Corporate Social Responsibility and Branding in Grocer Retailers: A Comparative Study over Italy and the $U K$, Musso F, Druica E. (eds.), Handbook of Research on Retailer-Consumer Relationship Development, IGI Global.

http://dx.doi.org/10.4018/978-1-4666-6074-8.ch019

Celaschi Flaviano (2008) Design as Mediation between Areas of Knowledge, Germak Claudio (ed.) Man at the Centre of the Project. Design for a New Humanism, Allemandi\&Co, Torino.

Colvin John, Blackmorea Chris, Chimbuyab Sam, Collinsa Kevin, Dentc Marc, Gossd John, Isona Ray, Roggerof Pier Paolo, Seddaiufa Giovanna (2014) In Search of Systemic Innovation for Sustainable Development: A Design Praxis Emerging from a Decade of Social Learning Inquiry, Research Policy, vol. 43, pp. 760-771.

http://dx.doi.org/10.1016/j.respol.2013.12.010

Costanza Robert, Patten Bernard (1995) Defining and Predicting Sustainability, Ecological Economics, vol. 15, n.3, pp.193-196.

http://dx.doi.org/10.1016/0921-8009(95)00048-8

Daly Herman, Cobb John (1989) For the Common Good, Beacon Press, Boston.

Elkington John (1994) Towards the Suitable Corporation: Win-Win-Win Business Strategies for Sustainable Development, California Management Review, vol. 36, n. 2, pp. 90-100. http://dx.doi.org/10.2307/41165746

Elkington John (1999) Cannibals with Forks: the Triple Bottom Line of 21st Century Business, Choice Reviews Online, vol. 36, n. 07, 36-3997-36-3997.

http://dx.doi.org/10.5860/choice.36-3997

Elkington John (2004) Enter the Triple Bottom Line. The Triple Bottom Line: does it All Add Up, vol 11, n. 12, pp. 1-16, Online: http://www. johnelkington.com.

Fiksel Joseph (2006) Sustainability and Resilience: toward a Systems Approach, Sustainability: Science Practice and Policy, vol. 2 n. 2, 1, pp. 4-21.

http://dx.doi.org/10.1109/emr.2007.4296420

Kathijotes Nicholas (2013) Keynote: Blue Economy- Environmental and Behavioural Aspects towards Sustainable Coastal Development, Procedia - Social and Behavioral Sciences , vol.101, pp. $7-13$.

http://dx.doi.org/10.1016/j.sbspro.2013.07.173

Locke Richard, Reavis Cate, Cameron Diane (2010) Fair Trade Coffee. The Mainstream Debate, Sloan Management Cases, pp. 1-23, http://www.thecasecentre.org

Macleod Sorcha (2001) Why Worry about CSR, Strategic Communication Management, vol. $5 \mathrm{n}$. 5, pp. 8-9.

Maple Peter (2008) The Spectrum of Philanthropy., vol. 5, Caritas, London.

Mirabella Nadia, Castellani Valentina, Sala Serenella (2014) Current Options for the Valorization of Food Manufacturing Waste: A Review, Journal of Cleaner Production, vol. 65, pp. 28-41. http://dx.doi.org/10.1016/i.jclepro.2013.10.051

Mohr Lois A., Webb Deborah. J., Harris Katherine. E. (2001), Do Consumers Expect Companies to Be Socially Responsible? The Impact of Corporate Social Responsibility n Buying Behavior. The Journal of Consumer Affairs, vol 35, n.1, pp. 45-72.

http://dx.doi.org/10.1111/j.1745-6606.2001.tb00102.x

O'Mahony Maria, Gwilt Alison (2010) Waste in the City Seminar, wasteinthecity.wikispaces.com, 3. 12. 1013.

Palmberg Irmeli, Kuru Jery (2000) Outdoor Activities as a Basis for Environmental Responsibility, The Journal of Environmental Education, vol 31, n 4, pp. 32-36. http://dx.doi.org/10.1080/00958960009598649 
Panusa Alessia, Zuorro Antonio, Lavecchia Roberto, Marrosu Giancarlo, Petrucci Rita (2013) Recovery of Natural Antioxidants from Spent Coffee Grounds, Journal of Agricultural and Food Chemistry, vol 61, n. 17, pp. 4162-4168.

http://dx.doi.org/10.1021/jf4005719

Parfitt Julian, Barthel Mark, Macnaughton Sarah (2010) Food Waste within Food Supply Chains: Quantification and Potential for Change to 2050. Philosophical Transactions of the Royal Society, Biological Sciences, vol 365, n.1554, pp. 3065-3081.

http://dx.doi.org/10.1098/rstb.2010.0126

Pauli Gunter (2010) The Blue Economy: 10 Years, 100 Innovations, 100 Million Jobs, Paradigm Publications.

Porter Michael, Kramer Mark (2011) Creating Shared Value: How to Reinvent Capitalism and Unleash a Wave of Innovation and Growth, Harvard Business Review, vol. 89, n. 1/2, pp. 6277.

Seelos Christian, Mair Johanna (2005) Social Entrepreneurship: Creating New Business Models to Serve the Poor, Business Horizons, vol 48, n.3, pp. 241-246. http://dx.doi.org/10.1016/j.bushor.2004.11.006

Simpson Mike, Taylor Nick, Barker Karen (2004) Environmental Responsibility in Smes: Does It Deliver Competitive

Tamborrini Paolo (2014) Innovation Design, Encyclopedia of Quality of Life and Well-Being Research / Michalos AC. Springer, Dordrecht

Torres Anna, Bijmolt Tammo, Tribo' Josep, Verhoef Peter (2012) Generating Global Brand Equity through Corporate Social Responsibility to Key Stakeholders, International Journal of Research in Marketing, vol. 29, n.1, pp. 13-24.

http://dx.doi.org/10.1016/j.ijresmar.2011.10.002

Vallaster Christina, Lindgreen Adam, Maon, Francois (2012) Strategically Leveraging Corporate Social Responsibility: A Corporate Brand Perspective, California Management Review, vol. 54, n. 3, pp. 34-60.

http://dx.doi.org/10.1525/cmr.2012.54.3.34

Vives Antonio (2006) Social and Environmental Responsibility in Small and Medium Enterprises in Latin America, Journal of Corporate Citizenship, vol 21, pp. 39-50. http://dx.doi.org/10.9774/gleaf.4700.2006.sp.00006

Wahba Hayam (2008). Does the Market Value Corporate Environmental Responsibility? An Empirical Examination, Corporate Social Responsibility and Environmental Management, vol 15, n 2, pp. 89-99.

http://dx.doi.org/10.1002/csr.153

\section{Notes}

${ }^{1}$ The PoliTO team is composed as follows: Scientific director Paolo Tamborrini; Responsible units PoliTO Silvia Barbero; team PoliTO Matilde Argentero, Milena Barbalinardo, Miriam Bicocca, Eleonora Fiore. 